\title{
A European Approach to Revision in Criminal Matters?
}

Joost Nan, Nina Holvast \& Sjarai Lestrade*

\section{Introduction}

This special issue includes contributions that address the extraordinary remedy of revision, designed to overturn a final criminal conviction that turns out to be wrong. The issue contains contributions on revision law in Belgium, France, Germany, Italy, the Netherlands, Poland, Spain, Sweden and England (including Wales and Northern Ireland). In this overarching contribution, we highlight several specific - and mostly common themes and challenges that stand out after learning about the different approaches to revision in the aforementioned European countries. ${ }^{1}$ We thereby aim to explore what different systems can learn from each other. We also explore whether a European approach to revision of criminal convictions is something to aim for. We will follow the general outline that is used in most contributions to this issue. We first provide a brief characterisation of the extraordinary remedy of revision and the interests involved (Section 2). This provides a common thread to discuss and reflect on the theoretical and practical issues in the following paragraphs. We will address the range of grounds for revision (Section 3), some important procedural aspects (Section 4) and the lack of empirical data on the functioning of the different mechanisms (Section 5). This will allow us to find some best practices for a properly functioning review mechanism in theory and practice - the need for which is not in question. Our approach will ultimately demonstrate that systems provide different solutions for certain problems and that no legal system is flawless. Nonetheless, to improve national revision procedures, it is valuable to learn from the experiences in other jurisdictions. We conclude that this special issue provides some important preliminary insights in this regard, but more research needs to be done to answer the question of whether a European approach to revision of criminal convictions would be desirable or not (Section 6).

* Joost Nan is Associate Professor at the Erasmus University Rotterdam. Nina Holvast is Assistant Professor at the Erasmus Universiteit Rotterdam. Sjarai Lestrade is Assistant Professor at the Radboud University Nijmegen.

1. We refrain from giving an overview of all the similarities and differences between these legal systems. The number of contributions and topics is simply too high and our space here is too limited.

\section{Revision as an Extraordinary Remedy}

All legal criminal justice systems aim to be diligent and their highest priority is to avoid making mistakes, both de facto and de jure. This explains the presence of regular procedures to review cases, such as appeal and (constitutional) cassation. Once proceedings have come to an end, the outcome has to be accepted, respected and enforced. The principles of legal certainty, finality and res judicata demand it (in short: litis finiri oportet). However, the reality is that making mistakes cannot be ruled out. Even after a criminal procedure has become final, it can turn out the verdict is wrong, either because of material circumstances which cast doubt on the culpability of the defendant or because of serious procedural defects. The interest of justice demands a post-proceedings review to redress these mistakes.

This interest of justice is more than just the interest of the convicted person and his or her legacy (after his or her death the next of kin can also submit the request). Revising criminal convictions is also in public interest. This particularly becomes apparent from the fact that all nine jurisdictions discussed in this special issue allow not only the convicted person and his or her legacy to file a request for revision, but also one or more public officials (such as a public prosecutor or a procurator general). The common absence of a time limit to submit such a request (in many but not all jurisdictions) also shows that revision transcends the individual's interests. With regard to revision, ultimately two interests are at stake. The principles of legal certainty, finality and res judicata on the one hand, and the principle of justice for the individual in specific and exceptional cases on the other hand. Only in special situations and under specific circumstances can the former principles be set aside to give way to the latter. It is plain to see that if the set-up of a revision mechanism is too strict, justice might not prevail. But if the set-up is too broad, the right would seriously endanger legal systems as a whole and the instrument might even collapse under all the (unjust) applications. The contributions to this special issue clearly demonstrate that the judiciary tends to exercise restraint when judging revision applications. Hence, for all the above-mentioned reasons, revision is truly an extraordinary remedy, in all jurisdictions. The most important challenge is finding the right balance between those competing interests. This challenge is the com- 
mon thread of this contribution when discussing the legal considerations and dilemmas regarding revision procedures. In the next section we will start by analysing the grounds for revision as mentioned in the different contributions to the special issue.

\section{Grounds for Revision}

In the jurisdictions discussed in this issue, two types of revision are possible. The most common, and undisputed, type is a revision to the advantage of the accused who is convicted. All jurisdictions offer this remedy. But there is also another type of revision, namely revision ad malam partem. This entails the reopening of proceedings to the disadvantage of the accused after criminal proceedings did not result in a conviction. This type of revision is regarded as problematic with regard to the ne bis in idem principle. It is only a feature in some of the jurisdictions' revision procedures and it usually requires more extraordinary circumstances than revision to the advantage of the convicted. Belgium, France, Italy and Spain do not accept revision ad malam partem. In France there was discussion (in 2014) to add this option, but it was ultimately rejected. Under specific, more restrictive circumstances, Germany, the Netherlands, Poland, Sweden and England allow for revision to the detriment of the accused. In the Netherlands it was enacted only in 2013 and in Germany an expansion is being seriously considered. This is an interesting development, but in this contribution, we will focus on the first type of revision.

Traditionally, jurisdictions have codified several grounds for revision in favour of the convicted. They include all sorts of falsa which have come to light after the conviction, such as a bribed judge, perjury of a witness or false documents. Other possible grounds are contradicting verdicts, or a situation wherein one of the provisions on which the conviction was based is declared unconstitutional or manifestly inconsistent with other provisions. All these grounds play only a modest role when it comes to actual revision cases. The so-called novum ground can be found in all jurisdictions and is most frequently invoked for revision (see infra). In addition to this, most countries also have a provision that makes revision possible in light of a judgement by the European Court of Human Rights. Spain introduced such a statutory provision in 2015; Italy and Sweden do not have such a possibility. In Italy, the Constitutional Court has created this opportunity in lieu of a provision.

A question that can be raised is whether some of the grounds for revision, especially the falsa, largely overlap with the novum ground (and perhaps even a judgement by the European Court of Human Rights could, with some creativity, be considered a novum). To streamline matters, some countries have narrowed down the grounds for revision to allow the reopening of a closedoff case to only a couple of grounds, such as Belgium (four grounds) and the Netherlands (three grounds). France even went as far as to narrow down its original four grounds to only one: the novum ground. The French legislature had the opinion that the other three grounds (the murder victim turned out to be alive, conflicting verdicts or a false witness statement), were encompassed by the novum ground. However, since this does not include all procedural defects, in the French system a judgement by the European Court of Human Rights is a second ground for revision. The French modification shows that it is possible to simplify the grounds for revision and have them centred around the novum criterion (supplemented with the possibility of reopening proceedings in case of a violation of the European Convention of Human Rights).

The novum is the most important ground for revision. Yet, it is also the most problematic one. A novum - in short and in general - is made up of the following three elements: 1) a fact or circumstance, 2) which was unknown to the court in the regular proceedings and 3) that would, had it been known, likely have changed the outcome of the trial (usually to an acquittal, acceptance of a justification or excuse, or the application of a more lenient sanction provision). However, the range of the novum ground depends on how its elements are formulated in the relevant provision and on the way courts interpret the novum ground in practice. Regarding the latter, France is an example of a jurisdiction in which the expansion of the criterion did not appear to have changed the likelihood of the Cour de révision et de réexamen to overturn a final conviction (see further, Section 5).

Since a different evaluation of evidence that the court has already considered cannot constitute a ground for revision, the question arises as to under which circumstances a different expert opinion can count as a novum. This proves to be especially problematic when no new material was examined, but a new technique has become available to examine the same material. Several jurisdictions struggle with this issue, and it remains a question of practice. Another question is if a change of law can be cause for revision. Some jurisdictions offer a provision for the event that a criminal provision is later declared unconstitutional, or allow revision if the conduct was decriminalised (see Belgium and Spain). In England, new arguments on points of law can be raised in the revision procedure. In other jurisdictions, this is not considered a reason for revision. In Germany and the Netherlands, a change of law is rejected as a ground for revision.

Another point on which legal systems differ from one another relates to how 'new' the fact or circumstance must be and to whom. For instance, should there be a reasonable explanation for the failure to adduce the evidence at trial, given that it was available to the defence at the time? The latter is the case in England. Some countries explicitly want to prevent the accused from holding on to evidence for the revision phase. In Germany, however, facts can still be deemed 'new' even if they have been discussed in the main proceedings, as 
long as the court did not take them into account unjustly.

A last discussion point concerns the question: in what situation is new evidence considered serious enough to assume it would have most likely or probably resulted in a different outcome of the legal procedure? In Poland, the new evidence has to demonstrate that the person involved is innocent. In the other countries, substantial doubt on the culpability of the convicted person is considered enough. Still, the courts are usually reluctant to accept that new evidence would have resulted in an acquittal or a different decision. In France, for instance, the standard was lowered by only demanding 'doubt' on the culpability of the convicted person. Any doubt would be enough, according to the French legislature. However, it is questionable whether this will make a difference in the assessment of revision requests by the Cour de révision et de réexamen. In the Netherlands there is an ongoing parliamentary debate on this topic, with several arguments made to lower the standard to 'an unsafe conviction' or 'serious or even reasonable doubt on the righteousness of the conviction'. The Dutch legislature has, up until now, not given in.

\section{Procedural Aspects}

This brings us to the procedural aspects. Apart from the variation in the interpretation of a novum in the various jurisdictions, there are different procedures to be undertaken to request a revision. First, the possibilities for requesting assistance in proving the existence of a novum (prior an application for revision) vary. In England, France and the Netherlands, the applicant has a formal possibility to request investigative measures before filing a request for revision, in order to prepare and substantiate a revision application. Belgium, Sweden, Spain, Poland, Italy and Germany do not offer such a possibility. In the latter countries, the applicant is expected to bring forward the evidence necessary to reopen the case on their own. However, in Germany if there are 'sufficient factual indications' that certain inquiries will lead to facts or evidence which could provide grounds for the permissibility of a petition to retry the case, a counsel will be appointed to the convicted person. This counsel is authorised to undertake investigations independently (such as questioning witnesses), but he or she does not have coercive powers for investigation. In Belgium, if the applicant demonstrates 'a strong suspicion' that the novum would have resulted in a different outcome if it had been known at the initial proceedings, the case will be referred to the revision commission. This commission investigates the case and gives advice to the court. Such investigation opportunities can support convicted persons in their quest for justice, while maintaining the extraordinary character of revision.

In Belgium, Italy, the Netherlands, Poland and Spain a request for revision must be submitted by a lawyer. In
England, France and Sweden a legal representative is not obligated to submit a review application. However, in the latter countries, if the request meets the formal requirements, the convicted person has a right to legal aid during the substantive procedure in front of the competent court. The requirement of legal representation could both increase the quality of applications and prevent the filing of applications that do not stand a chance (assuming that legal representatives would refrain from filing such cases). ${ }^{2}$ However, it could also turn out to be an obstacle if decent representation is (financially) unobtainable, as was described in our contribution on the Netherlands.

In Belgium, England and the Netherlands there are specific revision commissions that administer applications for revision. These commissions have a diverse composition and thereby ensure that a request for revision is not only examined by judges. In all three countries, the commissions have investigative powers and function as an advisory body to the courts. The commissions function independently from the courts. Furthermore, the advice of the commissions is not legally binding for the courts. In England, the commission also functions as a gatekeeper. Applicants cannot directly go to the court to have their case reviewed. A point of critique that is sometimes raised in relation to these commissions is that they assess requests too much in light of what the court would decide. In this regard, they do not act independently enough. ${ }^{3}$ At the same time, it is understandable that the committee considers the legal potential of a revision case.

In those countries without a specific revision commission, the main criticism is that the request for revision is judged within the court system itself, by judges. The room for additional perspectives is therefore limited and relevant insights from outsiders might be overlooked. It is also mentioned to be problematic that the convicted person must provide the evidence to prove there is a novum, while he or she might not have the financial resources to conduct research to substantiate his or her claim. In Sweden, Martinsson observes that a successful request depends heavily on the involvement of lawyers and journalists. ${ }^{4}$ However, lawyers do not have the means nor the time to investigate, while journalists do not have the legal skills. Martinsson therefore proposes the introduction of a Swedish review committee that administers applications for exonerations. However, even in the countries that offer possibilities to request investigative measures, the fact that the burden of proof lies too heavily on the convicted person is criticised.

If the critics are right, then the revision mechanisms are still ineffective in several ways. Certain procedural requirements, a revision procedure only involving judges and lack of sufficient legal and financial aid, could create insurmountable hurdles for convicted per-

2. These are the reasons for the Dutch legislature to enact such a provision.

3. See more in the contributions by Hoyle and Holvast, Nan and Lestrade. 4. See more in the contribution by Martinsson. 
sons to have their convictions adequately reviewed. These are serious potential problems and empirical data can help to provide more insight into whether these elements hinder the effective working of revision procedures.

\section{The Need for Empirical Data}

In order to understand whether the revision procedures indeed provide an effective remedy to correct wrongful convictions, it is necessary to have insight into how the revision legislation functions in practice. Unfortunately, a great problem when it comes to studying revision procedures is that in many of the studied jurisdictions, data concerning the revision procedures at work are exceptionally scarce. In most countries, even formal data that disclose the total number of applications for revision or the number of successful applications are unavailable. Nonetheless, by finding available data regarding one particular year for instance, or by looking at the cases in which compensation for wrongful convictions is rewarded, we can at least get a glimpse of what is going on in the different legal systems. In England and the Netherlands the situation is somewhat different, as in those countries more extensive empirical research has been conducted to gain insight into the functioning of (parts of) the revision procedures in practice. ${ }^{5}$ These studies do not only provide important quantitative data, but also provide qualitative material on how the involved institutions review cases. ${ }^{6}$

The limited data available reveal that in all jurisdictions the number of applications for revision that are submitted is not trivial. The numbers vary from about 20-30 cases per year in the Netherlands to $1,400-1,500$ cases a year in England. ${ }^{7}$ As expected with regard to the exceptional character of revision, in all jurisdictions most of the requests to review cases are rejected. Percentages of successful applications for review range from around $3 \%$ to about $10 \%{ }^{8}$ Of all cases that are ultimately reviewed, only some cases end up with the original conviction being nullified. It is however interesting to note that all jurisdictions for which data are available have at least some nullified convictions each year. ${ }^{9}$

It is, however, difficult to draw conclusions from merely these numbers. To start with, it is relevant to gain insight into whether these cases primarily concern minor offences or whether they concern, for example, homicide cases. In Spain and the Netherlands, a substantial portion of all successful revision cases concern cases regarding driving without a licence (and in the Netherlands driving without motor insurance is also a major category). In Germany, an empirical study of revision cases reveals that theft and robbery, and fraud are the most common offences, followed by highway offences. ${ }^{10}$ However, almost all contributions to this special issue also describe revisions of notorious miscarriages of justice concerning very serious offences. In these instances, the miscarriage has usually also instigated public and academic discussion regarding the case. Considering that in many jurisdictions not all revision cases are published, it is difficult to gain insight into the precise composition of the supply of revision cases.

Furthermore, the revision procedures all have different set-ups and occupy a different position within the criminal justice systems of the different countries. For instance, jurisdictions have different possibilities for appeal within the regular system, which can affect the need for post-conviction review. In a system where possibilities for appeal are more limited, such as in England, it is not surprising that more people sought to use post-conviction review opportunities. ${ }^{11}$

Finally, the total number of issued applications provides only little information about the actual number of wrongful convictions, given that - for a start - we do not know the percentage of wrongfully convicted persons who actually submit an application. As mentioned, different factors can inhibit the wrongfully convicted from bringing their case forward. Hence, the available empirical data do not allow us to draw any general conclusions about how the revision procedures function in the jurisdictions discussed in this special issue. We agree with many of the contributors to this special issue $^{12}$ that it is important that more data becomes available to learn whether the revision procedures do in
5. However, some empirical research has also been conducted in Germany; see Lindemann \& Lienau's contribution, and also in Sweden, see Martinsson's contribution.

6. See more in the contributions from Hoyle and Holvast, Nan \& Lestrade.

7. Other available data reveal that in France from 2014 to 2019 about 110-140 applications per year were submitted, in Germany 1,000 applications were submitted in the year 2018, in Spain 4,982 requests for review were resolved between 1995 and 2019 and in Sweden 383 applications were submitted in 2015. In Poland, Italy and Belgium no data are available on the total number of applications. Of course, one should be aware that these countries (and the number of court cases they handle) greatly differ in size.

8. In Spain about $90 \%$ of applications are dismissed. In Sweden an approval rate of $3 \%$ was found for the year 2015. In England and Wales, The Criminal Cases Review Commission has referred approximately $3 \%$ of cases to the appeal courts. In France over the years from 2015 to 2019 4 to 9 cases were approved while in total 118 to 145 applications were submitted each year.
9. In Poland from 2010 to 2018, on average compensation was awarded to 16 wrongfully convicted persons; in Sweden 7 cases were approved in 2015. In Belgium between 2000 and 14 July 2015, decisions were taken on 50 requests for revision and in 10 of these cases, the original conviction was nullified. In Italy a total of 191 compensation requests pursuant to Art. 643 CCP were accepted in the period between 1991 and 2019. In France from 2012 to 2019, on average there were 2.2 nullifications per year. In the Netherlands from 2015 to 2019, there were on average 7 well-founded applications for revision. The empirical data on Germany also seem to suggest that there are at least some nullifications each year; see Lindemann \& Lienau.

10. See Lienau and Lindemann on this study.

11. See also in this regard M. Killias, 'Errors Occur Everywhere - But not at the Same Frequency: The Role of Procedural Systems in Wrongful Convictions', in C.R. Huff and M. Killias (eds.), Wrongful Convictions \& Miscarriages of Justice: Causes and Remedies in North American and European Criminal Justice Systems (2013).

12. See most noticeably Martinsson in this issue. 
practice offer an effective remedy and what factors potentially impede its functioning.

\section{Conclusion}

From the contributions in this special issue, which cover nine different western European jurisdictions, it becomes clear that the importance of providing revision as a legal instrument to overturn wrongful criminal convictions, is undisputed. Revision in favour of the accused is, we conclude, generally seen as an indispensable and thus important remedy in any criminal justice system. ${ }^{13}$ At the same time, revision in case of an unjust conviction is an extraordinary measure, only applicable in exceptional circumstances, because justice will normally be done in the regular procedure. The provisions for revision are therefore usually formulated restrictively. We furthermore observe that there exists no unity on the grounds for revision and that not all jurisdictions allow for an application after a verdict by the ECtHR.

The available empirical data on revision in practice show that the grounds for revision are indeed restrictively applied by the courts. This makes it difficult for convicted persons to have their final conviction reviewed. In many instances this is amplified by the lack of funds for adequate legal representation (which is frequently mandatory to file a request) and the lack of facilities to investigate the existence of new facts or circumstances, which could constitute a novum. Some countries, such as France and the Netherlands, have broadened the novum ground for revision and enacted a procedure which allows (certain) convicted persons to ask the public prosecutor or procurator general for an investigation into a possible novum, prior to submitting a request for revision. Experiences in the Netherlands show some modest, positive results. But this pre-procedure is by no means a panacea for all situations, as most requests for a further investigation are inadmissible because no viable lead to a novum is presented. In both France and the Netherlands, even after legal possibilities were broadened, criticism on the procedure remained.

The various contributions to this special issue show both several similarities and differences between legal systems on the grounds for revision and the procedural aspects. There is not one single approach that stands out or proves to be superior to the others. A perfect revision mechanism, if it exists, will have to be the result of a patchwork of existing features, which fits within the specific legal system where it functions. However, the absence of reliable empirical data makes it particularly difficult to determine whether the revision mechanisms are functioning adequately and offer convicted persons sufficient access to this review remedy.
All jurisdictions have in common that they are aiming to find a balance between the principles of legal certainty, finality and res judicata, and the principle of justice. All jurisdictions also have in common that they seem to struggle to find the right balance between these principles. This special issue points to various 'best practices', as well as possible defects and challenges. The descriptions of the revision procedures in all these different jurisdictions, as well as their challenges, offer legislatures valuable material to reassess and improve their own systems. However, this special issue only marks the beginning of a more thorough comparative analysis of revision procedures. In order to make impactful research-based improvements, and perhaps even create mutual standards, more data are needed about the functioning of the systems in practice. Such further studies would allow national legislatures to learn more from international experiences. They can potentially also enable the European Commission and the Council of Europe to assess whether possible unwarranted differences in the national legal systems and malpractices in the functioning of these systems call for a European approach to redress wrongful criminal convictions. 